\title{
Die praktische Konkordanz von Kompetenzen
}

Entwickelt anhand der Jurisdiktionskonflikte im europäischen Grundrechtsschutz

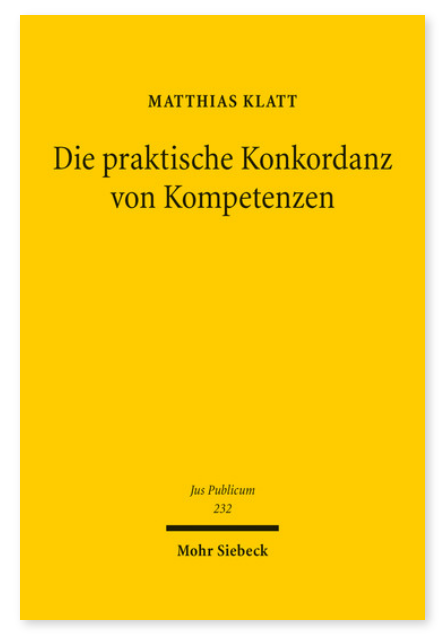

2014. XXIII, 471 Seiten. JusPubl 232

ISBN 978-3-16-153050-0

DOI 10.1628/978-3-16-153050-0

eBook PDF $134,00 €$

ISBN 978-3-16-153017-3

Leinen $134,00 €$
Kompetenzkonflikte sind in Mehrebenensystemen allgegenwärtig, zumal in einer globalisierten Welt. Erstmalig begreift Matthias Klatt Kompetenzen nicht als Regeln, sondern als Prinzipien. Anhand der Leitidee einer praktischen Konkordanz von Kompetenzen analysiert er die Jurisdiktionskonflikte im europäischen Grundrechtsschutz. Neben einer neuen Typologie dieser Konflikte wird eine Theorie formeller Prinzipien vorgelegt, die Ansätze in der von Alexy begründeten Prinzipientheorie weiterentwickelt. Mit ihrer Hilfe formuliert der Autor ein Abwägungsmodell der Kompetenz. Dieses verteidigt einen Mittelweg zwischen starren Hierarchien und Appellen an richterliche Zurückhaltung. Damit wird eine flexible Lösung präsentiert, die anders als bloß beschreibende Beobachtungen normative Leitlinien entwickelt. Gegen einen skeptischen Pluralismus wird ein kraftvolles Plädoyer für einen pluralistischen Konstitutionalismus entfaltet.

Matthias Klatt Geboren 1973; Studium der Rechtswissenschaften in Göttingen und München; 2003 Promotion; Wiss. Mitarbeiter am Bundesverfassungsgericht; Mitglied der Jungen Akademie an der Berlin-Brandenburgischen Akademie der Wissenschaften und der Leopoldina - Nationale Akademie der Wissenschaften; Junior Research Fellow am New College, University of Oxford; seit 2008 Inhaber der Juniorprofessur für Öffentliches Recht, Europarecht, Völkerrecht und Rechtsphilosophie an der Universität Hamburg; 2013 Habilitation und Lehrstuhlvertretung an der Humboildt-Universität Berlin.

Jetzt bestellen:

https://mohrsiebeck.com/buch/die-praktische-konkordanz-von-kompetenzen-9783161530500?no_cache=1 order@mohrsiebeck.com

Telefon: $+49(0) 7071-923-17$

Telefax: $+49(0) 7071-51104$ 